\title{
RECONSTRUCTING SOCIO-POLITICAL URBAN-RURAL INTERACTIONS USING VIEWSHED ANALYSIS: THE LATE BRONZE AGE AT RAMAT BET SHEMESH, ISRAEL.
}

\author{
YITZHAK PAZ AND MICHAL BIRKENFELD
}

Israel Antiquities Authority, Ha-Marpe 5 Street Har Hozvim Jerusalem, e-mail: yitzhakp@israntique.org.il,michalbi@israntique.org.il

Received: $22^{\text {th }}$ April 2017, Accepted: $7^{\text {th }}$ January 2018

\begin{abstract}
The archaeological research conducted during the last two decades at the Judean Shephelah testifies for one of the most turbulent regions in the land of Israel during the Late Bronze Age. This stands in contrast to the scarce historical record that relates to it. The geographic region of Ramat Bet Shemesh encompasses important information about socio-political relations between the small rural settlements and hamlets and the city-states that dominated the area from the west. Advanced GIS modelling is one of the main research tools that enables us to reconstruct various aspects of these interactions. In this paper, the results of viewshed analyses are presented, suggesting that these interactions are defined, among other things, by a solidarity between small rural occupations that resist territorial rigid inner division of the landscape.
\end{abstract}

Keywords: Ramat Bet Shemesh, Late Bronze Age, city states, rural villages, GIS, Viewshed Analysis

\section{INTRODUCTION}

Located at the northern portion of the Judean Shephelah in central Israel, the area of Ramat Bet Shemesh is a well-defined geographic region; measuring c. $30 \mathrm{sq} \mathrm{km}$. It is bordered from all directions by streams and tributaries: the Yishi stream from the north, the Zanoah stream from the east, the Ha'elah stream from the south and the Yarmouth and Yishi streams from the west (Fig. 1). This area is an enclosed ecological system, rich in water sources and arable land providing ample opportunities for both plant cultivation and pasturage (and see Dagan, 2011: Ch. 10).

Since the 1990's, large-scale archaeological and environmental surveys have been conducted in this region, as part of a large development project (Dagan, 2011). These surveys, that were augmented by numerous excavations in recent years, resulted in large digital databases, providing an outstanding record of the human exploitation of a single region, from prehistoric to modern times (Fig.1). The large databases, the well-defined geographic region and the variety of archaeological data enable us to closely examine changing patterns of landscape utilization throughout several millennia. 
Fig. 1: Location map showing Ramat Bet Shemesh and bordering streams (Yishi, Zanoah, ha-Elah and Yarmouth) as well as all surveyed sites

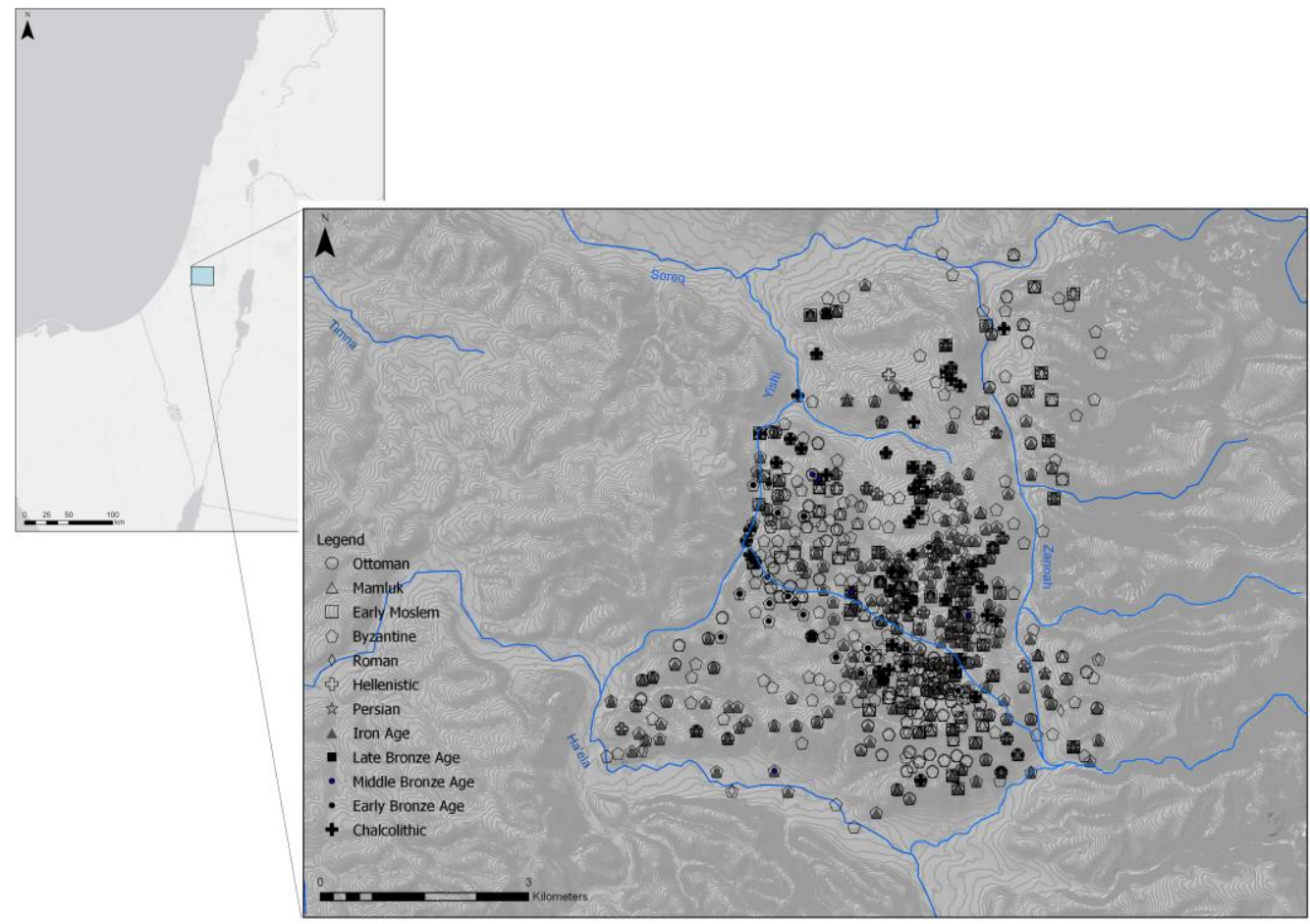

The regional archaeological project is focused on the relations between landscape and humans in antiquity. This project considers landscape as a major factor that affected humans and was effected by them throughout time. Since its very beginning, the Ramat Bet-Shemesh project involved extensive use of GIS applications, mainly for the recording of both environmental and archaeological data (Sharon \& Zionit, 2011). In recent years, use of GIS has entered a new phase with the application of advanced analysis and modelling methods that enable us to deal with the enormous databases with relative ease and to examine the intricate spatial patterning of human-landscape relations and how they changed through time.

Viewshed analysis is one of the landscape exploration methods used in the Ramat Bet Shemesh Project. We believe that using different scales of viewshed analysis, from the single-site to the regional level, allows for a deeper understanding of the spatial distribution of visual control and dominance within the regional system, as well as testing hypotheses regarding the division of power and territorial boundaries. In this paper, we attempt to pose a suggested reconstruction for Late Bronze Age socio-political interactions using viewshed analysis. The relationship between 'urban' sovereign settlements and 'rural' occupations is discussed. The analysis of the visual landscape together with the spatial distribution of the sites will shed light on a unique aspect of socio-ideological structure in the region during the period. 


\section{THE LATE BRONZE AGE IN THE JUDEAN SHEPHELAH}

The Judean Shephelah was one of the regions that stood in the middle of a turbulent era in the late second millennium BC. The rather scarce historic records that are available, mainly Egyptian documents such as the Amarna letters, portray a period of instability, characterized by violent incidents that threatened the vulnerable Canaanite city-state system ( $\mathrm{Na}$ 'aman, 1988). The archaeological evidence from the Shephelah clearly reflects this, as traces of violent destructions are found at major mounds such as Tel Lachish (Stratum VI, see Ussishkin, 1993: 904-905), Tel Bet Shemesh (Ziffer et al., 2009: 333), Tel Batash (PanitzCohen, 2006: 326-327) and Tel Azeqah (Gadot, 2015: pers. comm.). These destructions seem to date between the $14^{\text {th }}$ and the $12^{\text {th }}$ centuries BC, during the Late Bronze Age II-III periods (henceforth LBA).

Very little is known from historical records about the city-states that occupied the northern Shephelah (Na'aman, 1988). While Lachish is mentioned in some five Amarna letters (Na'aman, 1988:93-95), other urban entities, such as Tel Bet Shemesh and Tel Azeqah, are not mentioned in any of these records. The only possibly relevant historical record, Amarna letters nos. 273-274, mention a female sovereign of an unnamed city-state that some scholars have identified with Tel Bet Shemesh (Goren et al., 2004:277; Ziffer et al., 2009).

The lack of historical records is more acute when it comes to the smaller settlements that characterize the Ramat Bet Shemesh region during the LBA. In a sole cuneiform tablet from Tell el-Hesi (EA 333), the ruler of a settlement named Yaramu is mentioned. The identification of Yaramu with Tel Yarmouth, as suggested by Albright, was rejected by Na'aman, who doubted the existence of LBA remains at the site (Na'aman, 1988: Footnote 17). However, remains dated to the $13^{\text {th }}-12$ th centuries $B C$, were recently recorded at the site by the French CNRS expedition (Jasmin, in press).

The Ramat Bet Shemesh archaeological survey (Dagan, 2010) has revealed 13 sites dated to the LBA (Fig. 2). They were divided by Dagan (2011: 252-254) into categories, according to their estimated size: 'findspots', 'settlements' (including scattered structures, farmsteads and villages) and cities (one burial site was also included). The sites that can relate to settlements (12 out of 13, leaving the burial aside) can be organized in two clusters, situated on two sides of Nahal Yarmouth (Fig. 2) and include four 'settlements' (the 'villages' of Khirbet el-Alia and Tel Yarmouth, the scattered structures at Site 248.1 and a 'farmstead' at Site 286.1, i.e. Khallat el-Himara, but see below) and five 'findspots' (site nos. 219, 222, 237.1, 237.2, 381).

Excavations were conducted on behalf of the IAA at all four 'settlement' sites. It seems that except for Tel Yarmouth, which reflects a continuous occupation between the $13^{\text {th }}-12^{\text {th }}$ centuries BC, the other sites reflect more ephemeral occupations that can be roughly dated to the $12^{\text {th }}$ century BC (see also discussion below). It seems that the severe crisis that occurred in the late $12^{\text {th }}$ century BC in southern Canaan did not pass over Ramat Beth Shemesh, as at least some of the LBA sites were deserted during the latter part of the period. The survey results indicate that this sub-region was almost devoid of settlement during the early $2^{\text {nd }}$ millennium BC (Dagan, 2011: 248-252). However, at Tel Yarmouth, no clear break was discerned between the Stratum V of the $12^{\text {th }}$ century BC (late LBA) and Stratum IV of the late $12^{\text {th }}$ century BC (Early Iron Age; see Jasmin, in press). All in all, it is plausible that the late $12^{\text {th }}$ century BC crisis was the main factor for the demise of the LBA settlement system in the region. 
Fig. 2: LBA sites at Ramat Bet Shemesh

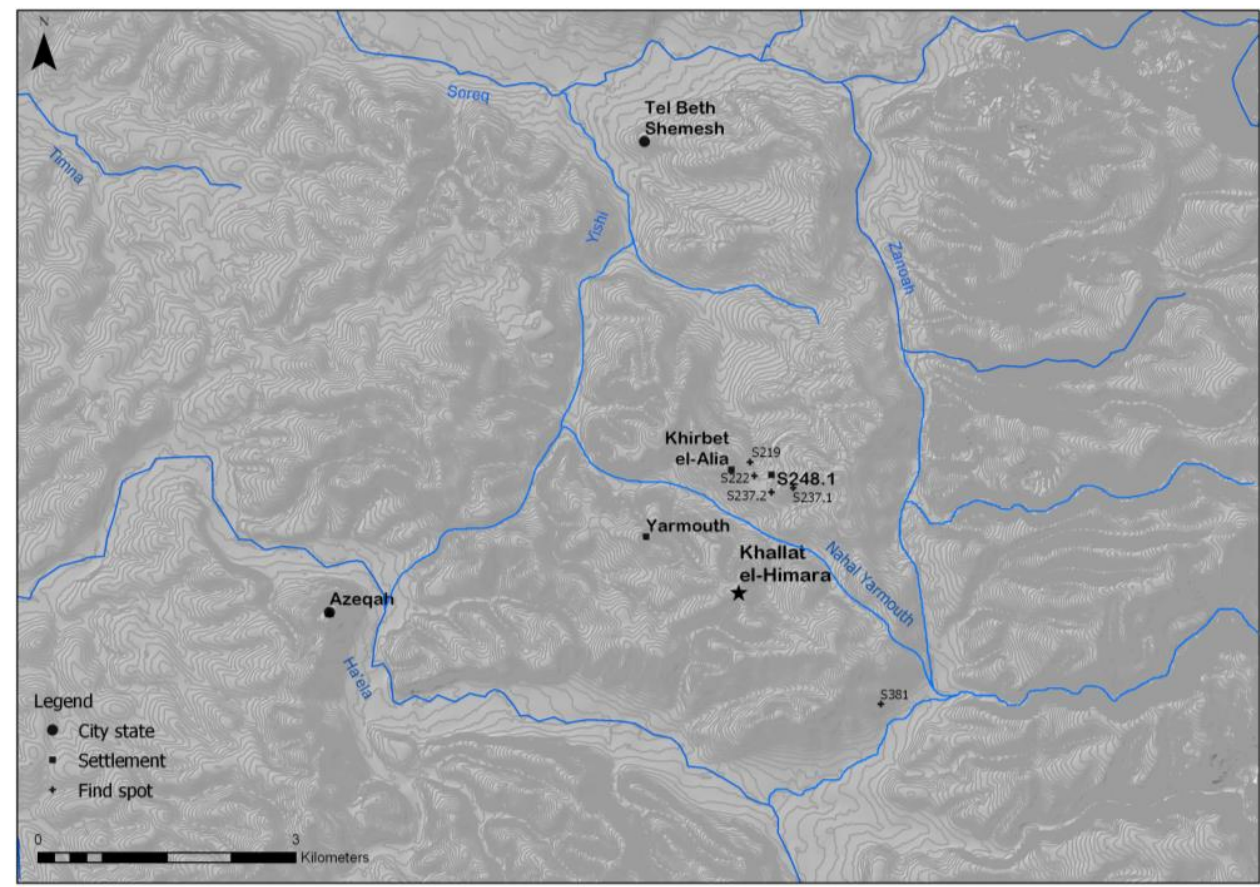

\section{Reconstructing Late Bronze Age Socio-Political Urban-Rural Interactions}

The first attempt to reconstruct LBA socio-political relations at Ramat Bet Shemesh was made by Y. Dagan (2004). Dagan described two city states or 'kingdoms' that dominated the Shephelah during the LBA: Gath-Tel Zafit, to which the sites of Tel Batash, Tel Bet Shemesh and Tel 'Azeqah were subordinate, and Lachish, to which sites like Tel 'Eitun and Tel Beit Mirsim could have been connected (Dagan, 2004:2679). Within Ramat Bet Shemesh, he noted two focal points of settlements: northern, in the immediate vicinity of Tel Bet Shemesh, and southern, on both sides of the Yarmouth stream, where most of the surveyed sites were located (Dagan, 2000:164-165). However, the relations between the small agricultural sites and the city-states remained unclear and Dagan refrained from outlining borders or territorial boundaries within Ramat Bet Shemesh itself (Dagan, 2000:170). Moreover, the inability to securely date the surveyed sites to a specific phase within the LBA (Dagan, 2004:2679) further complicated the discussion, as the contemporaneity of the different sites could not be ascertained.

In his reconstruction of the political organization of city-states in southern Israel in the $13^{\text {th }}$ century BC, Jasmin (2006) suggested that the Ramat Bet Shemesh sites were not directly controlled by the larger political entities that are found west and south of the region (Jasmin, 2006: Figs. 2-4) but were rather bounded within the territory of Gath-Tel Zafit, similar to the suggestion made by Dagan (ibid: Fig. 6). An examination of the territorial map as presented by Jasmin, reveals an interesting pattern: the three major city states - Gezer, Zafit and Lachish, are not located at the center of their territory, as would have been expected according to 'central place theory' (Christaller, 1933), but they are rather located at the western (Gezer and Zafit) or northern (Lachish) parts of their territory and seem to employ a three-tiered settlement system. If we accept this scheme, the territory of Tel Zafit was ruled 
from the west by the major city state that existed at Tel Zafit, with a second tier located eastwards, that included, among other sites, Tel Bet Shemesh and Tel 'Azeqah, and further east, the third tier of rural settlements of Ramat Bet Shemesh. Tel Bet Shemesh and Tel 'Azeqah, may thus have been acting as 'sub-regional centers' (Jasmin, 2006; Fig. 1).

The recent excavations at Ramat Bet Shemesh ameliorate our understanding of local chronology and support the possibility of a flourishing urban entity at Tel 'Azeqah was clearly able to compete with the city-state reconstructed at Tel Bet Shemesh. It is most likely that the two city-states co-existed at least during the $13^{\text {th }}-12^{\text {th }}$ centuries BC, even though it is doubtful whether they reached their apogee at the same time: Tel Bet Shemesh was violently destroyed by the end of the $13^{\text {th }}$ century BC and regained its strength only the end of the LBA (Bunimovitz: pers. comm.), and the settlement at Tel 'Azeqah reached its zenith during the $12^{\text {th }}$ century BC but reflects continuous occupation throughout the LBA (Lipschitz, Gadot and Oeming, 2012).

Reviewing the LBA site distribution at Ramat Bet Shemesh (Fig. 2) can highlight several aspects relating to this debate. First, the area is physically divided into two main topo-geographic units by Nahal Yarmouth, which was probably flowing throughout the year and served as the main water source of the region. Second, most of the 13 LBA settlements recorded during Dagan's survey are arranged alongside this route, on both opposing banks of Nahal Yarmouth. In this respect, it seems that contrary to the division suggested by Dagan, the LBA settlement system at Ramat Bet Shemesh can be divided into two different units, divided by the Yarmouth stream: the northern unit includes the large settlement of Tel Bet Shemesh, smaller settlements at Tel Zanoah, Kh. el-Alia and Site 248.1, and several small 'findspots' (site nos. 219, 222, 237.1, 237.2). The southern unit includes a larger settlement, i.e. Tel 'Azeqah, smaller settlements at Tel Yarmouth and at Khallat el-Himara (and see below) and a single 'findspot' (Site 381).

It can thus be suggested that the political boundaries in Ramat Bet Shemesh followed the physical natural feature of Nahal Yarmouth which divided the area not only topographically but also politically into two units, each dominated by a city state: the northern by Tel Bet Shemesh and the southern by Tel 'Azeqah. Most interesting is the distance of c. $4 \mathrm{~km}$ that is kept between the city states and the agricultural sites, with 'findspot' 381 being the most remote point from Tel 'Azeqah, c. $6 \mathrm{~km}$, still well within a day's walking distance from the main site.

As discussed above, the scarce historical records enable only a glimpse into the socio-political realm of the Judean Shephelah and they focus primarily on the city states that were in contact with Egypt. It is nonetheless important to try and reconstruct connections between the small settlements and try to evaluate their relations with the larger city-states. Within this context, the recent excavations of Khallat el-Himara, one of the 13 rural LBA sites surveyed by Dagan, are of great importance to clarify issues relating to local LBA chronology and, as a focal of everyday activity, to shed light on how the environment and its resources were exploited, as well as on site location choices.

With the scarcity of historical records, our understanding of these exploitation patterns will enable us to clarify how the settlement system operated; how activities were organized throughout the landscape and how human-land relations were intertwined within the local socio-political order. With the relative wealth of both archaeological and environmental information available at Ramat Bet Shemesh, the application of GIS analyses methods has proven very useful in elucidating such patterns. In this paper, we wish to present how the use of viewshed analyses to explore the visual characteristics of the ancient landscape can assist in exploring our models and hypotheses. As part of the landscape archaeology paradigm, analyses of visibility and inter-visibility has long served the study of site location choices and 
social interactions (i.e. Fraser, 1983; Garcia-Moreno, 2013). Our main aim in the viewshed analyses at Ramat Bet Shemesh, was to test the above presented hypothesis regarding the division of power between Tel 'Azeqah and Tel Bet Shemesh. In order to explore the different levels of landscape utilization, different levels of analysis were used, from the single site to the regional viewpoint. First, the site of Khallat el-Himara is presented, followed by the analysis methodology. Finally, results are discussed in within the larger, regional framework.

\section{THE Site OF KHALlat EL-Himara}

The site of Khallat el-Himara (henceforward KEH, grid 198741-623318/198817-623386; see Fig. 3) is located on a limestone outcrop, over $400 \mathrm{~m}$ high, surrounded by small tributaries. The site is situated on a flat area in the south-eastern side of the hill, surrounded by moderate slopes where many rock-cut installations, as well as an EBA settlement, were recorded. Excavations at the site were conducted in 1996 by E. Eisenberg and D. Sklar on behalf of the Israel Antiquities Authority and in 2012 by Y. Paz, on behalf of the IAA (Eisenberg \& Sklar, 2000; Paz, forthcoming). These two excavations fully explored the LBA settlement.

Fig. 3: General view of the 2012 excavated area, looking west

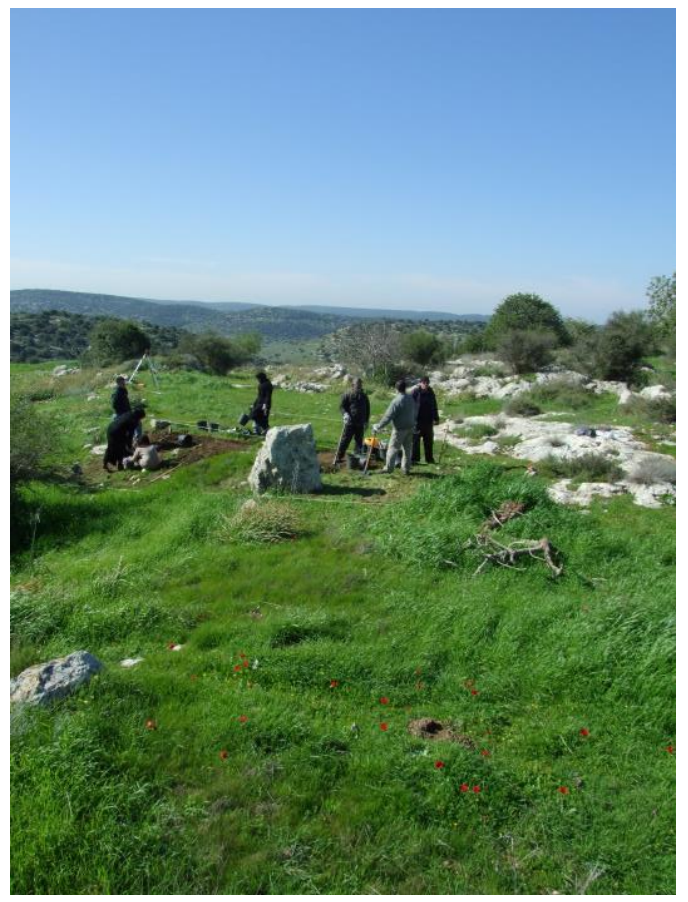

The 1996 excavations revealed meager architectural remains, including wall fragments and pavements that were assigned to a farmhouse. The associated pottery consisted primarily of store jars and cooking pots (Eisenberg \& Sklar, 2000). The 2012 excavations concentrated on two main locations: a southern area was annexed to the 1996 excavation squares to better 
comprehend the partial architectural remains exposed earlier and the northwestern area was focused on a slightly elevated region in which the prominent feature was a huge standing stone (Fig. 4).

Fig. 4: Architectural plan showing Standing Stone S1 and its immediate surroundings, excavated in 2012

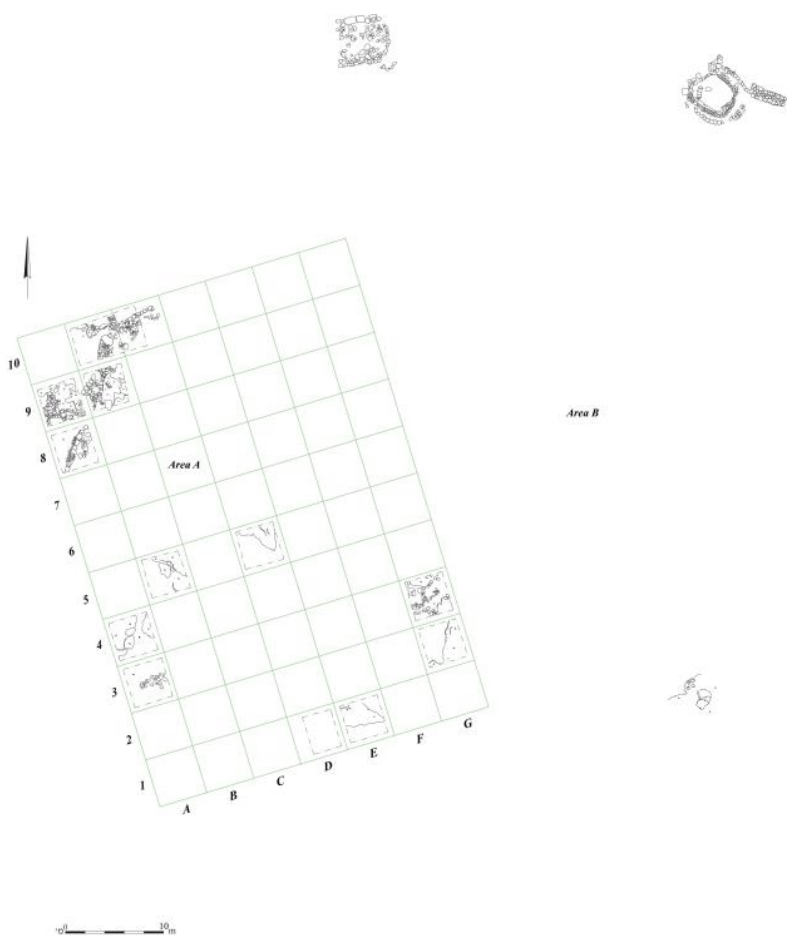

The excavation of the southern location did not furnish a better understanding of the nature of the architecture already exposed by Eisenberg and Sklar. No complete plan of a farmhouse or houses was achieved and we cannot establish whether the flimsy wall fragments detected have any clear connection to one or more structures. The shallow accumulation on bedrock and recent agricultural activities were also factors that added to the paucity of the architectural remains. However, similar to Eisenberg and Sklar, cooking pots and storage vessels composed the majority of the pottery assemblage. In total, it seems that the southern cluster of structures in the LBA settlement was very limited in size, covering c. 700 sqm.

At the northwestern area of excavation, an elevated rock shelf was exposed, on which was a standing stone (S1) that no doubt served as a focal point (Fig. 5). The base of Standing Stone $\mathrm{S} 1$ was $1.25 \mathrm{~m}$ wide, its maximum width was $1 \mathrm{~m}$ and its maximum height, $1.30 \mathrm{~m}$. It was situated in a northwest-southeast direction facing southwest. Its western side seems to 
have been intentionally worked to create a straight face, while its eastern side was grooved. A brown flint vein running through its southern side may have added to its unique appearance. In the middle of the upper portion of the stone, a rounded depression was created, bordered on both sides by elevated 'crests'. When looking between these two 'crests' in a $240^{\circ}$ azimuth, the rounded hill of Giv'at Yesha'ayahu, c. $5 \mathrm{~km}$ southwest, appears directly in the middle of the depression (Fig. 6). In addition, the two 'crests' seem to be exactly fixed as markers of two rounded ridges between which a depression is found, both ridges located right below Givat Yesha'ayahu, in the southwestern horizon. A view in the exact opposite direction (in a $60^{\circ}$ azimuth northeast) is barred by thick modern vegetation but points to the direction of Khirbet el-Keik, a prominent spur in which settlement remains from the prehistoric to the Byzantine periods were found during surveys and excavations (Dagan, 2010: 178-180). A view in the same direction further northeast reaches Horvat Zanoah, where a plausibly contemporaneous LBA occupation existed (Dagan, 2010: 132-146). These characteristics seem to indicate that the Standing Stone S1 was deliberately placed in its location and possibly had a symbolic-ideological purpose.

\section{Fig. 5: The standing stone, view to the north}

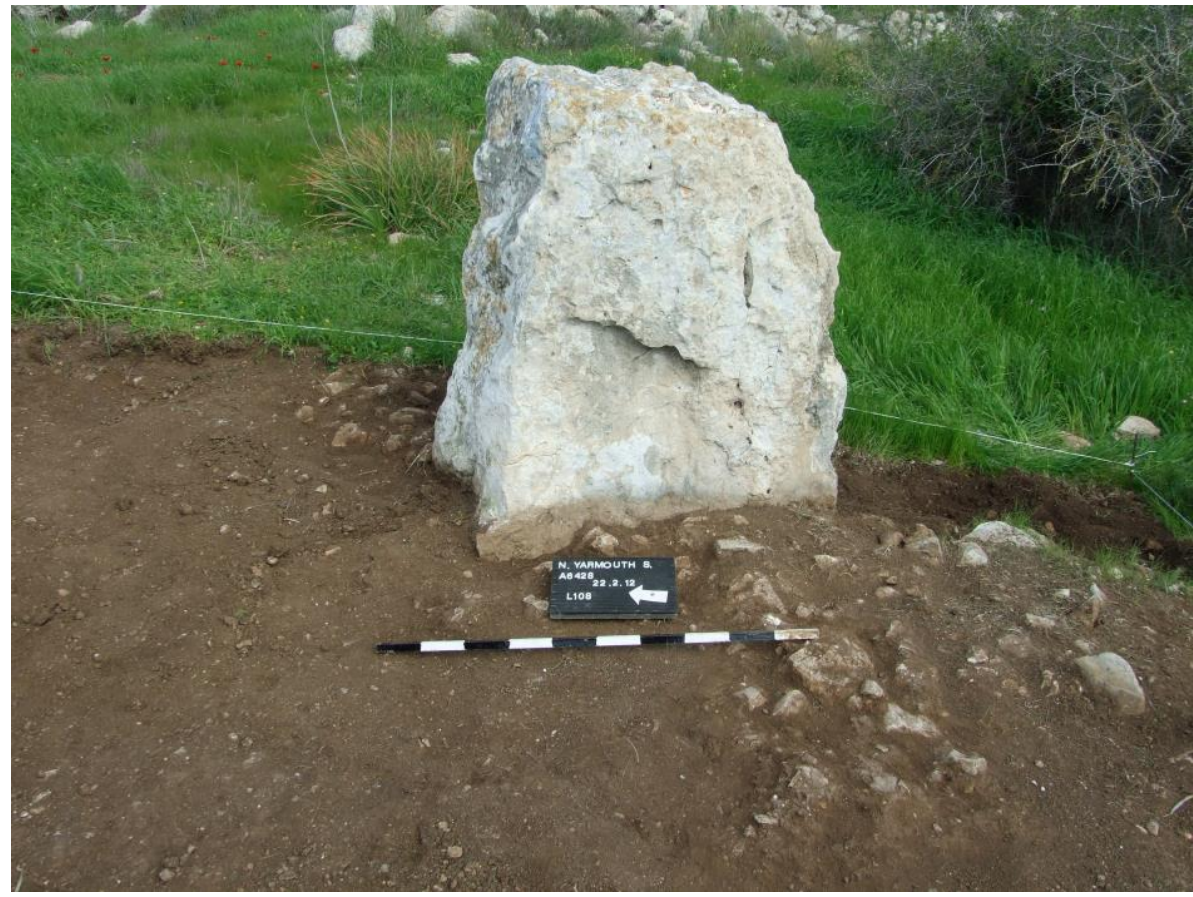

Immediately to its southwest, remnants of a structure that was probably connected to Standing Stone S1 was exposed. Within this structure, LBA pottery sherds were found, yet no complete or restorable vessels were recovered. The repertoire of shapes was limited and no imported types were found. As a rule, most of the vessels were made from brownish-orange clay that contained light, white inclusions, probably of limestone. Most frequent among the ceramic forms were storage jars (25 indicative sherds out of 76, or $33 \%$ ) and cooking pots (the same number, $33 \%$ ). Bowls of various types comprised $26 \%$ (20 indicative sherds out of 76), and jugs only $5 \%$ of the assemblage (4 indicative sherds). 
The best parallels to the pottery of KEH may be sought in late LBA $\left(12^{\text {th }}\right.$ century BC) contexts at sites such as Tel 'Azeqah (S. Metzer: pers. comm.), Tel Yarmouth (Jasmin, in press), Tel Batash (Stratum VI; see Panitz-Cohen, 2006) and Lachish (Stratum VI; Ussishkin, 2004), and see further discussion below. The LBA remains at KEH thus seem to represent a small rural settlement. Standing Stone S1, on the other hand, may possibly shed light on an interesting, lesser-known aspect of daily life during this period.

Fig. 6: The Giva'at Yesha'ayahu hill, seen between the 'crests' of Standing Stone S1, looking southwest

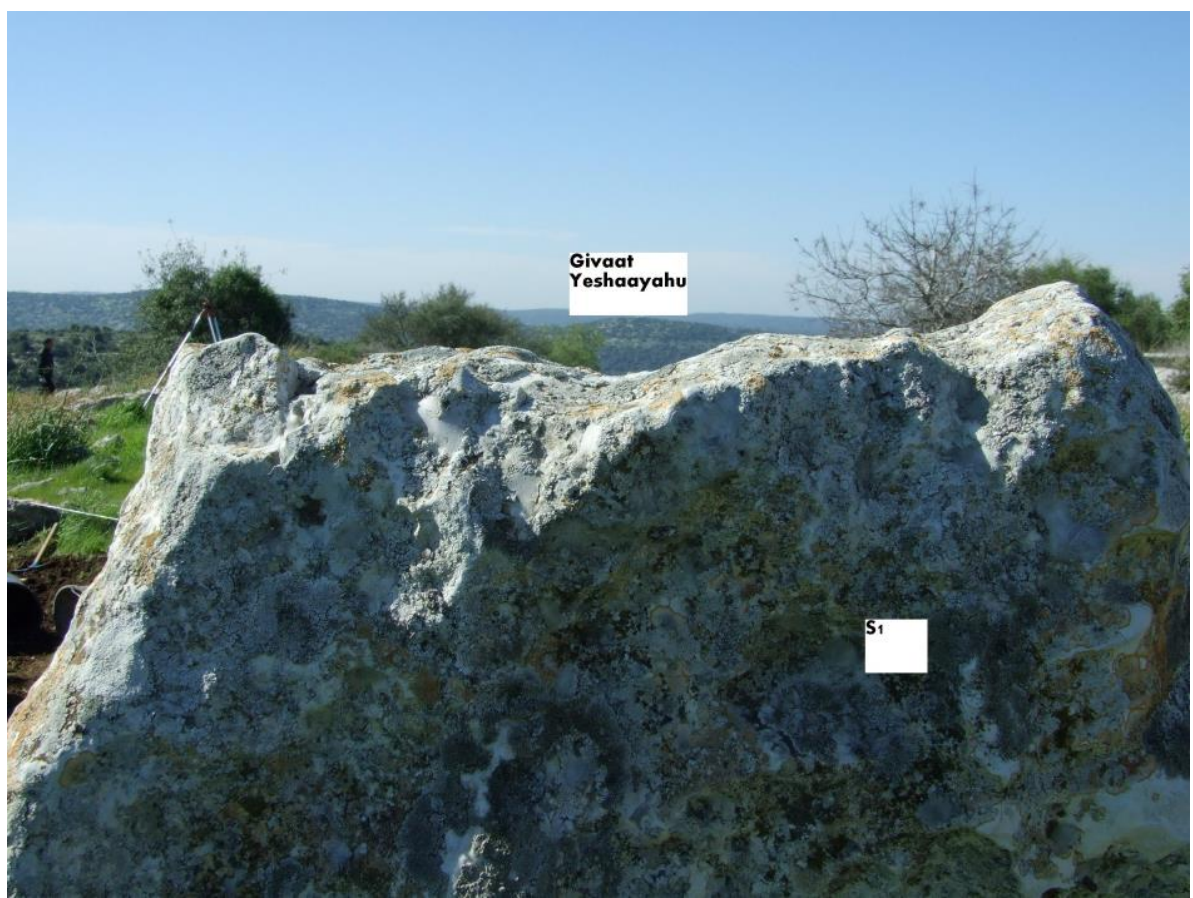

\section{THE VIEWSHED ANALYSIS}

Viewshed analysis is a long-standing methodology in archaeological studies, long before the advent of GIS technologies in the field. GIS applications, however, have made viewshed analysis more feasible; while methodologically, the analysis has remained very much the same, relying on the measurement of 'line of site' and 'field of view', technically, it has become much easier; while prior viewshed analyses was based on field observations and manual calculations, GIS-based analysis uses a DEM (Digital Elevation Model) to calculate 'lines of site' between raster cells, and enables straightforward calculations of areas of visibility and inter-visibility, and thus allows for the quantification of the visual perception of the landscape (see Wheatley \& Gillings, 2000 for a full discussion). It must be considered, however, that viewshed analysis (whether GIS-based or not) does not and cannot fully recreate the exact visibility qualities of a specific location, since in reality, visibility is affected by many factors, such as weather conditions, state of vegetation as well as subjective capabilities of the viewer. Since GIS-based viewshed is mostly based on topography, and even though current software allows for the calculation of the effects of factors such as earth 
curvature and light refraction, it should be taken as representing a somewhat over-optimistic result, of what could have been visible under perfect conditions.

In this research, viewshed analysis was conducted using ESRI ArcGIS 10.1 and the viewshed toolset. The DEM used has a $10 \mathrm{~m}$ cell size and was created based on $5 \mathrm{~m}$ contour lines elevation map. The earth's curvature was taken into account, with the default 0.13 refraction value. Several viewsheds were explored, with an emphasis on three observer points: Tel Beth Shemesh, Tel 'Azeqah and the standing stone at KEH. A cumulative viewshed map of the visible areas from all settlement sites was also generated. The results of the viewshed analysis are presented in Figs. 7-9.

Khallat el-Himara, as stated above, is located on a limestone hill, ca. $400 \mathrm{~m}$ asl. As a result, it supports a rather extensive viewshed, with direct lines-of-sight in all directions (Fig. 7). What is interesting is that the site, and most specifically the Standing Stone S1, had a direct line-of-sight to all contemporary settlements in Ramat Bet Shemesh, including both city-states at Tel Beth Shemeh and Azeqah as well as the smaller settlements at Kh. El-Alia, Tel Yarmouth and Site 248.1. The smaller 'findspots', on the other hand, were apparently not visible from the site.

\section{Fig. 7: Viewshed from KEH; areas visible marked in orange}

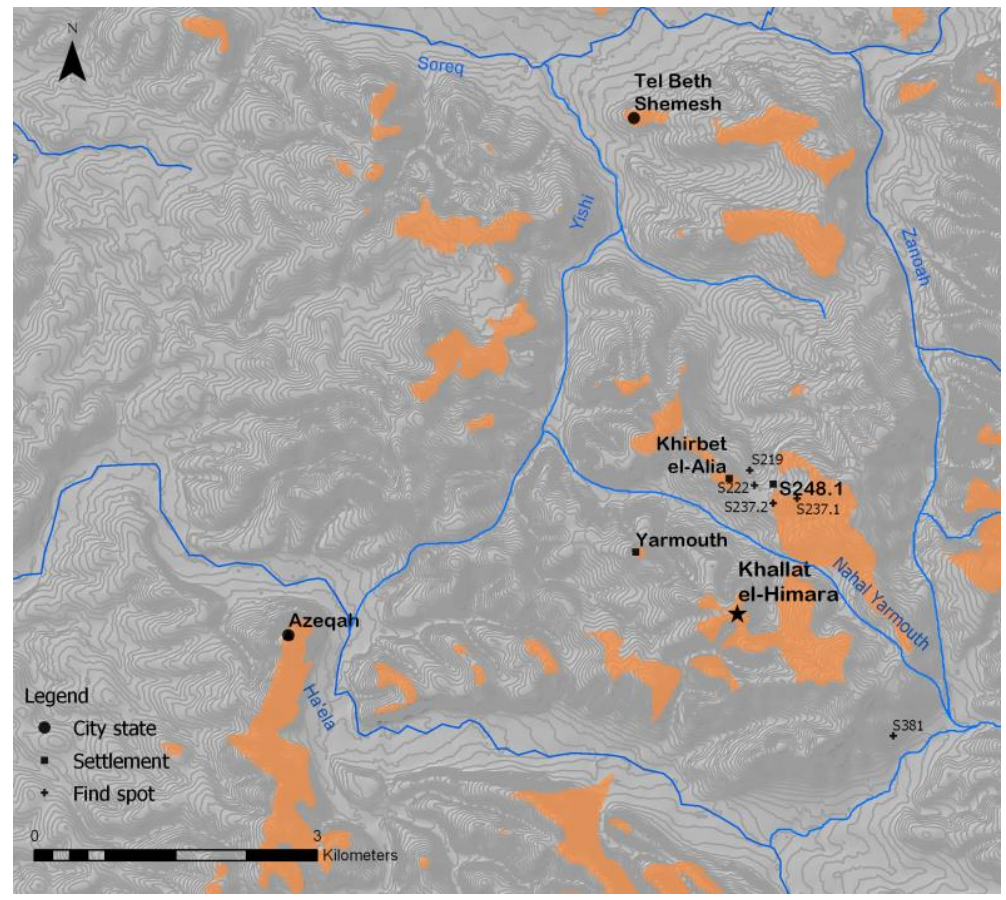

On the regional scale, Fig. 8 shows the respective viewsheds of the two city-states at Tel Beth Shemesh and Azeqah. Both sites were clearly located in significant vantage points, allowing for extensive viewsheds of the Ramat Bet Shemesh area. It is important to note that each of the two viewsheds seems to control a different, juxtaposed territory, with very little overlap between them. In fact, it seems that the landscape of Ramat Bet Shemesh was equally divided between areas controlled from each of the city-states, with the two opposing ridges on both sides of Nahal Yarmouth being the only areas controlled from both sites. 
Fig. 8: Viewshed of the two city-states; the viewshed of Tel Beth Shemesh (in green) and that of Tel Azeqah (in red)

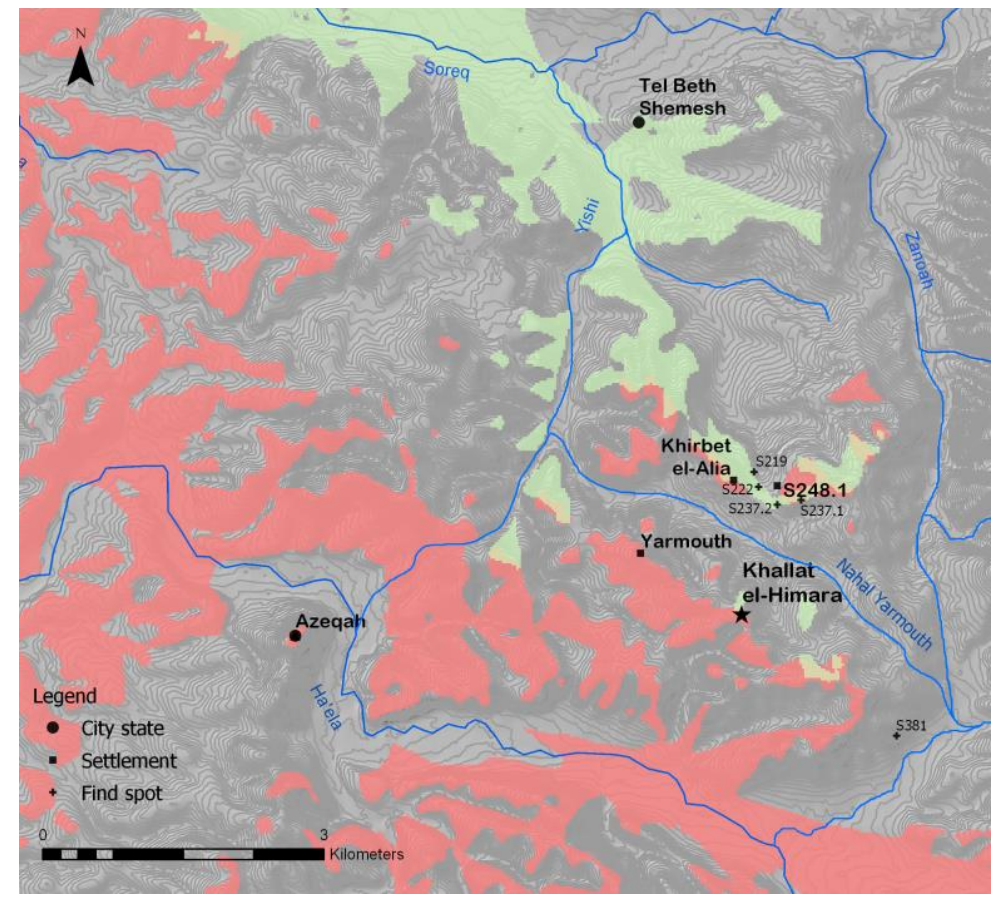

Fig. 9: Cumulative viewshed of the LBA settlements at Ramat Bet Shemesh

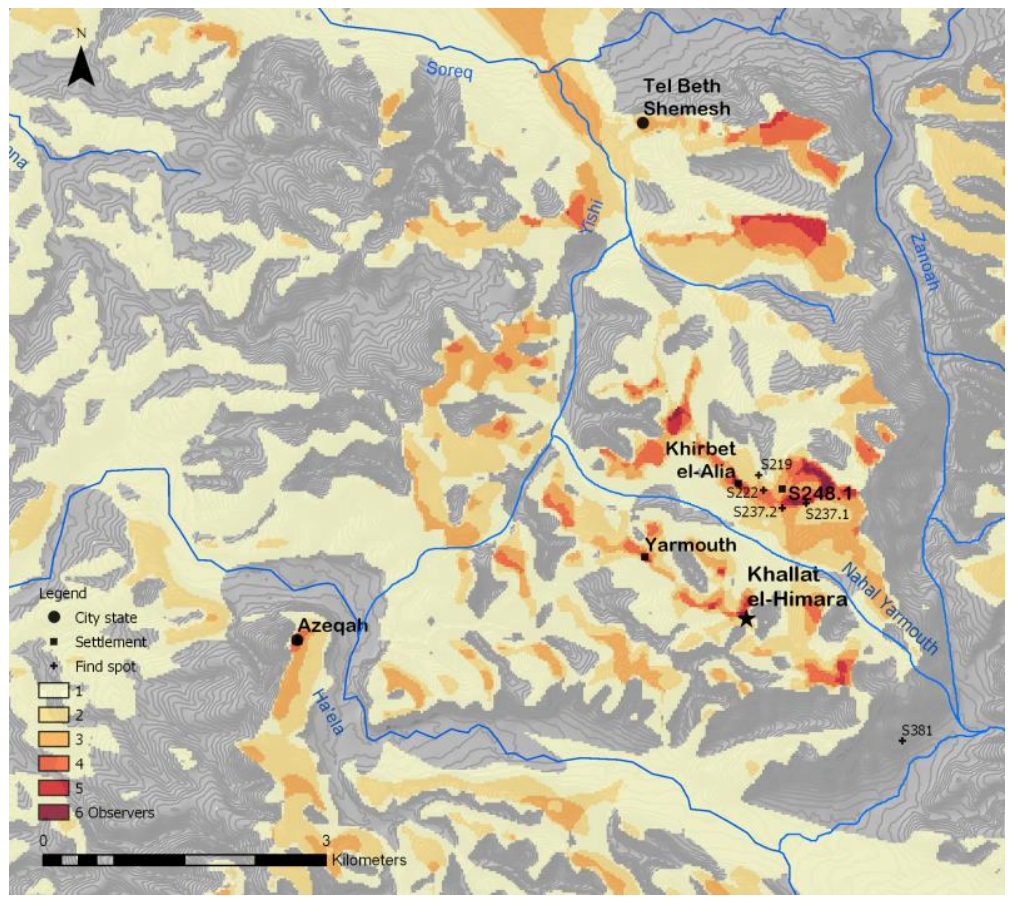


A similar pattern was revealed in the cumulative viewsheds of the six settlement sites (Fig. 9). Here again, the areas on both banks of Nahal Yarmouth stand out significantly as areas visible from most if not all settlement sites. It seems that more emphasis was put on the inter-visibility between the smaller settlements than their visual connections with the supposedly sovereign city-states.

\section{DISCUSSION}

\section{Khallat el-Himara within the LBA Settlement System of the Judean Shephelah}

The results of the viewshed analysis support the hypothesis that divided the Ramat Bet Shemesh LBA landscape between north and south, following the path of Nahal Yarmouth. This division was clearly reflected by the equivalent division of the visual-landscape between the two possible sub-regional centres of Tel Bet Shemesh and Tel 'Azeqah. Each site controls its 'section' of the landscape, while the theorised 'border', i.e. the route of Nahal Yarmouth, is visibly controlled from both sites. In the centre of this area of dual-command, sits the site of $\mathrm{KEH}$.

Khallat el-Himara, though very fragmentarily preserved, may present evidence of a small settlement site that existed on the summit of one of the highest hills in the Judean Shepelah. This location was probably of importance, as can be seen in modern facilities exploit the hill slopes (terrace walls, watch-towers that overlook olive orchards that occupy the southern slopes). Eisenberg (2000) defined KEH as a farmstead or a small agricultural village, based on its material culture (Eisenberg, 2000). We concur that the settlement at KEH may very carefully be defined as a 'small village', somewhat parallel to the settlements at Tel Yarmouth, Tel Zanoah and Kh. el-Alia, which were also estimated as 'villages', c. 0.4-1 ha in area (see Jasmin 2006: Fig. 1, Sites 81, 83, 85; ibid:164). It is probable that the small settlement cultivated vine and olive orchards that were located at the slopes of the hill and were watered by the tributaries of Nahal Yarmouth. The lack of imported pottery from KEH versus the Cypriote and Mycenaean wares that were found at Tel Yarmouth Stratum VI may suggest that KEH is parallel to Stratum V at Yarmouth (LBIII/Iron IA, $12^{\text {th }}$ century BC).

Nonetheless, the commanding location of the site on the crest of the hill may have had another aspect, reflected by Standing Stone S1, which was deliberately located on the highest point in the settlement, from which specific landscape features can be observed (see discussion above). The completely different appearance of the stone from each side is a well-known feature in sacred megalithic sites in Neolithic Europe (e.g. 'Long Meg and her daughters' in Cumbria, Britain; Service and Bradbery 1979:221). Such a standing stone, a most uncommon feature for a farmstead, may hint at a symbolic or cultic function, connected perhaps with the adjacent Structure 126 (see above). The complete lack of cultic paraphernalia in the excavated area versus the abundance of cooking and storage vessels may pose some difficulties to this possibility.

Yet another possibility is that the site at KEH was not a permanent settlement and was inhabited seasonally, following the agricultural cycles. In this case, it can be defined as a 'hamlet' (see Jasmin, 2006: 164), and one can reconstruct different episodes of usage of the crest of the hill: while it was used for residence in one occasion, it could have taken a possible symbolic/cultic capacity at another. The chronologic relation between these two (or more) theoretical capacities is by no means clear and they could well be contemporaneous.

Within this regional framework, it seems that KEH had extensive visual connections with all the main contemporaneous villages in its surroundings. This is well attested in the viewshed analyses results. In fact, KEH and especially the Standing Stone S1, were probably 
visible from settlements located both north and south to Nahal Yarmouth and thus could have had connections with both the northern cluster (related to Tel Bet Shemesh) and the southern cluster (related to Tel 'Azeqah).

\section{The Unifying Natural Landscape over the Diversifying Political Border}

The rigid topo-geographic settings that could have created a physical border-line between the domains of the two city states mentioned above must have stood in contrast to efforts that may have been made by the small rural settlement points (be it villages, hamlets or find spots) to retain solidarity and unity, even in symbolic means. This point was attested while we examined a GIS viewshed analysis model that was conducted on this region. Figure 2 clearly shows that all six sites, located on the ridge north to Yarmouth stream, stand in a narrow line that can be defined as a buffer zone between the area controlled by Tel Bet Shemesh and the one controlled by Tel 'Azeqah. All six seem to have visibility conditions that enable them direct view of the sites of the southern unit, mainly the site that existed at the acropolis of Tel Yarmouth and KEH. Moreover, the standing stone of KEH was visible from each and every of the small sites (save, perhaps Find Spot 381). This stone and in accordance, were deliberately situated in a point from which all settlement locales were visible, including both Tel Bet Shemesh and Tel Azeqah. While one may explain the location of the northern cluster of sites in the practical need to be close to the water sources and to agricultural soils (as described above), another explanation could be given, especially in light of the unique location of the KEH standing stone.

The rivalries between LBA city states were one of the hallmarks of the period and they were reported in length elsewhere (see e.g. Finkelstein and Naaman 2005). In many cases, the small rural settlements were the victims of these rivalries, as they were raided and sometimes even destroyed by city-state governors (see the case of Shunem in the Jezreel Valley, raided by Labayu ruler of Shechem; Finkelstein \& Na'aman, 2005).

The cultural, economic and social relations between these small sites that in 'peaceful' times would have cooperated and shared similar cultural lives, were probably extremely limited by border lines and political restrictions that were set by city-state rulers. Thus, it is possible that the six sites of the northern cluster, dominated by Tel Bet Shemesh, were not allowed, for example, to trade with KEH and Tel Yarmouth, dominated by Tel 'Azeqah. It can be also suggested that their mere location was connected with a need to mark the boundaries of city state control. The way to resist these restrictions was found in their location, the six sites cluster being located on a ridge from which the southern sites were visible and vice versa. In addition, the standing stone of KEH was a cultural beacon, probably seen from each and every settlement point, reminding the population of their shared culture, ideology, beliefs and social identity.

\section{SUMMARY}

The settlement pattern of Ramat Bet Shemesh during the LBA is defined by small rural settlements that were located in two clusters north and south of the Yarmouth river. These clusters were probably related and subjected to the urban settlements at Tel Bet Shemesh and Tel 'Azeqah.

A thorough GIS-based research has shown that the two clusters were connected by direct lines-of-sight. The prominent standing stone at KEH may have served as a cultural unifying beacon. 


\section{REFERENCES}

Christaller W. (1933). Central Places in Southern Germany. English Edition 1968. Translated by C.W. Baskin. Englewood Cliff: Prentice-Hall.

Dagan, Y. (2004). The Results of the Survey: Settlement in the Lachish Region. In: Ussishkin, D. ed. The renewed archaeological excavations at Lachish (1973-1994) (3674-3692). Tel Aviv.

Dagan Y. (2010). The Ramat Bet Shemesh Regional Project: The Gazatteer (IAA Reports 46). Jerusalem: Israel Antiquities Authority.

Dagan Y. (2011). The Ramat Bet Shemesh Regional Project: Landscapes of Settlements: from the Paleolithic to the Ottoman Period (IAA Reports 47) Jerusalem: Israel Antiquities Authority.

Eisenberg E. and Sklar D. (2000). Nahal Yarmouth. Hadashot Arkheologiyot 111: 109.

Finkelstein I. and Na'aman N. (2005). Shechem of the Amarna Period and the Rise of the Northern Kingdom of Israel. Israel Exploration Journal 55(2):172-193.

Fraser, D. (1983). Land and Society in Neolithic Orkney. Vol. 1. Bar Company.

Garcia-Moreno, A. (2013). "To See or to Be Seen. Is That the Question? An Evaluation of Palaeolithic Sites' Visual Presence and Their Role in Social Organization." Journal of Anthropological Archaeology 32, no. 4: 647-58.

Goren, Y., Finkelstein, I., \& Naaman, N. (2004). Inscribed in clay : Provenance study of the Amarna tablets and other ancient Near Eastern texts. (Tel Aviv University, Institute of Archaeology, Monograph Series ; 23). Tel-Aviv: Emery and Claire Yass Publications in Archaeology.

Jasmin M. (2006). The Political Organization of the City-States in Southwestern Palestine in the Late Bronze Age IIB (13th Century BC). In: A. M. Maeir, and P. de-Miroschedji. eds. "I Will Seek the Riddles of Ancient Times", Archaeological Studies in Honor of Amihai Mazar on the Occasion of his Sixtieth Birthday (pp. 161-190). Winona Lake.

Jasmin M. (in press). The Late Bronze and Iron Age Remains at Tel Yarmouth.

Lipschitz O., Gadot Y. and Oeming M. (2012). Tel Azekah 113 Years After. Near Eastern Archaeology 75(4):196-206.

Mazar, A. (2006). The Shephelah According to the Amama Letters, in I. Finkelstein and N. Na'aman (eds.), The Fire Signals of Lachish (281-299). Studies in the Archaeology and History of Israel in the Late Bronze Age, Iron Age, and Persian Period in Honor of David Ussishkin, Winona Lake 2011.

Panitz-Cohen N. (2006). The Pottery of Strata XII-V at Tel Batash. In: N. Panitz-Cohen and A. Mazar eds. Timnah (Tel Batash) III: The Finds from the Second Millennium BC (Qedem 45) (pp. 9-150). Jerusalem: Institute of Archaeology, Hebrew University.

Service A. and Bradbery J. (1979). The Standing Stones of Europe. London: Trafalgar Square Publishers.

Sharon I. and Zionit G. (2011). Geographic Information Systems: Introduction, Methodology and Description of Basic Coverages. In Y. Dagan ed., The Ramat Bet Shemesh Regional Project: Landscapes of Settlements from the Paleolithic to the Ottoman Period (IAA Reports 47) (pp. 63-94). Jerusalem: Israel Antiquities Authorities.

Tufnell O. (1958). Lachish IV. London: Oxford University Press. V

Ussishkin, D. (1993). Lachish, Tel. NEAEHL 3:897-911. 
Ussishkin D. (2004). Section B: The Level VI Pottery from Areas D and GE. In D. Ussishkin ed. The Renewed Archaeological Excavations at Lachish (1973-1994) (pp. 1235-1242). Tel Aviv: The Tel Aviv University Institute of Archaeology.

Wheatley D. and Gillings M. (2000). Vision, Perception and GIS: Some Notes on the Development of Enriched Approaches to the Study of Archaeological Visibility. In G. R. Lock ed. Beyond the Map: Archaeology and Spatial Technologies (pp. 1-27). Amsterdam: IOS Press.

Ziffer I., Bunimovitz S. and Lederman Z. (2009). Divine or Human? An Intriguing Late Bronze Age Plaque Figurine from Tel Beth Shemesh. Ägypten Und Levante/Egypt and the Levant 19:333-341. 